\title{
Workspace Visibility Graph Analysis (VGA) for Concentration Privacy and Group Relations in the Open-Plan Office Environment
}

\author{
Yeon-Koo HONG and Uoo-Sang YOO \\ $\mathrm{PhD}$ Candidate, Department of Psychology, University of Surrey \\ Professor, School of Architecture, Chonnam National University
}

\begin{abstract}
The present study explored the applicability of Visibility Graph Analysis (VGA) techniques to workplace design research. Six types of VGA measures in Depthmap encompassing visual connectivity, three types of visual integration, mean depth, and visual entropy were employed for the analysis of individual privacy for task concentration and group relationship behavior in the open-plan office environment. Data comprised 136 workers in 6 open-plan offices filled with low-paneled $(1.2-1.5 \mathrm{~m})$ cubicle workspaces. For the statistical analysis, Spearman's rho correlations and t-tests were applied for the spatial and behavioral measures. The results showed that workspace VGA measures have a potential to be useful information to account for workers' concentration privacy and, limitedly, also informal relationships with team members. Visual entropy values especially offer reliable information to predict various aspects of office workers' privacy behavior while visual integration can be used to account for the workers' sense of trust in group relations. The study also discussed the limitation of VGA applications to the workplace context.
\end{abstract}

Keywords : VGA (Visibility Graph Analysis), Space Syntax, Privacy, Group Relations, Office Layout

\section{INTRODUCTION}

Space syntax techniques in workplace design research have been useful in explaining workplace behavior in relation to the spatial configuration of open-plan offices (e.g. Rashid et al., 2009; Peponis et al., 2007; Penn et al., 1999). When applied to workplace design research, space syntax techniques help to analyze the lines of movement and visibility at both the local and global levels on office plans in relation to the workers' social and interpersonal behavior at various group or department levels in an organization (e.g. Bafna, 2003, Steen et al., 2005).

A main implication from the space syntax analyses is that visibility and accessibility control via the shape of cubicles or the degrees of enclosures of individual workstations have more systematic effects on the occupants' behavior than global decisions such as the imposition of an overall circulation grid (Bafna, 2005). In other words, the space syntax studies have shown the importance of individual workspace geometries and degrees of enclosure for the workers' interpersonal visibility and accessibility controls for their individual as well as interpersonal behavior.

This point is well supported by many workplace behav-

\footnotetext{
Corresponding Author: Uoo-Sang YOO, Professor

School of Architecture, Chonnam National University

77 Yongbongro, Bukgu, Gwangju, 500-757, Korea

Tel:+82625301644 e-mail: usyoo@jnu.ac.kr

This study was financially supported by Chonnam National University, 2008

This work was supported by the Grant of the Korean Ministry of Education, Science and Technology"(The Regional Core Research Program/Biohousing Research Institute)
}

ior studies showing that individual workspace visibility and accessibility takes a primary role for various behavior including worker interactions and relationships, communication, team process, as well as privacy issues (see McCoy, 2002; Sundstrom 1987).

However, since space syntax studies mostly used group level of spatial measures in the literature, they seem to lack workspace visibility and accessibility analysis at an individual level for such behavioral issues as privacy and group relations, which are the two key behavioral elements for successful knowledge work (e.g. Brill et al., 2001; CABE, 2005; Herman Miller, 2008).

In this respect, the present research explored workspace visibility and accessibility through space syntax VGA techniques for individual privacy and group relations behavior in the open-plan office environment.

\section{VGA FOR PRIVACY AND COLLABORATION}

(1) VGA in Depthmap

Visibility graph analysis (VGA) is a spatial analysis technique for urban and building spaces which was first introduced by Braaksma and Cook (1980) and then developed by Turner et al. (2001). The technique evolved from the combination of techniques used in Space Syntax and the methods used in the analysis of small-worlds networks by Watts and Strogatz (1998) and then incorporated into Depthmap, a spatial network analysis software, offering various types of VGA measures (see Turner, 2001).

Six types of VGA measures in Depthmap are investigated in the context of workspace spatial analysis: 1) 'visual connectivity' - the number of locations which can be 
seen from a workspace point, 2) 'visual mean depth' - the shortest path to a workspace from all the points (nodes) on the map, 3) 'visual Integration' - normalized version of the mean depth of a workspace point, 4) 'visual entropy' - a degree of asymmetric or symmetric distribution of visible locations from a workspace point to all of the points on a map. Visual integration is further categorized according to the normalization methods: 'integration HH' - suggested by Hiller and Hanson (1984), 'integration P-value' - normalized by p-values, and 'integration Tekl' - suggested by Teklenburg et al. (1993) (see Turner, 2004 - for the detailed introduction).

\section{(2) Concentration Privacy}

Architectural privacy generally refers to visual and acoustical isolation supplied by the physical design of an environment. Psychological privacy is defined as a 'sense of control' over interaction, environmental stimuli and/or information between the self and others for job functioning (see Sundstrom, 1986; Kupritz, 2000 - definitions and concepts of workplace privacy). By these definitions, architectural privacy which is of visual and acoustic privacy helps people achieve psychological privacy which is essential for effective task concentration.

The present research specifically uses the term 'concentration privacy' operationalized 'privacy condition for mental concentration'. By this definition, concentration privacy refers to 'a sense of control' over incoming interactions and/or the environmental stimuli such as speech, views, noise, etc. to avoid interruption and/or distraction for individual task concentration (cf. Sundstrom, 1986; Sundstrom, Burt \& Kamp, 1980; Kupritz, 2000). Thus, concentration privacy is distinguished from general concepts of privacy such as visual and auditory privacy in built-environment and it is more specific than the psychological concept of privacy. This research explored the effects of visibility and accessibility conditions measured by VGA on individual workers' concentration privacy and also some privacy related behavior in the open-plan office environment.

\section{(3) Group Relations}

The present research also explores the effects of workspace visibility and accessibility on 'group relations' via workspace VGA measures. The term 'group relations' is defined in the present research at an interpersonal level by two specific factors: task coordination and informal relationships. These variables are set to represent general aspects of the task and affective dimensions of interpersonal relations in relation to group process and cohesion (e.g. Chang \& Bordia, 2001; Janz et al., 1997).

Thus, 'task coordination' encompasses such areas of group process as member cooperation in solving work problems, sharing of work information, and the speed of group decision making. 'Informal relationship' covers the affective and informal aspects of intragroup relations: bonds, friendship, and trust between the members.

(4) Research Questions
To explore six types of workplace VGA measures for privacy, interaction and group relations behavior, the present research sets out two explorative research questions:

RQ1: Are workspace VGA measures useful to explain privacy behavior for task concentration?

RQ2: Are workplace VGA measures useful to explain group relations behavior?

\section{METHOD}

(1) Setting and Participants

A company of six open-plan office floors in the company building participated in the research. Out of 145 office workers located in the open office settings, the total number of workers that came to data entry was 136 . The company consists of four departments: marketing, design and research, support and management, and project design. The six open office settings are filled with low-paneled workspaces with partition heights between $1.2 \mathrm{~m}$ and $1.5 \mathrm{~m}$ which allows sufficient eye contact and interaction over the partitions when standing whilst providing visual blocks when seated.

\section{(2) VGA Measures}

Depthmap v8.15 was used for the 6 VGA measures at the knee level. For the VGA measures of each workspace, a chair position was assumed at the midpoint along the width of and attached to each desk (cf. white square points on the VGA maps). Only the workspaces of the participants were selected for the data which were then extracted from Depthmap table for the following categories: 1) visual integration - $\mathrm{HH}, 2$ ) visual integration - $\mathrm{P}$ value, 3) visual integration - Tekl, 4) visual mean depth, 5) visual connectivity, and 6) visual entropy.

Figure 1 and 2 are two sample VGA maps of the 4th floor for an illustration purpose. On the maps, the blackcolored areas represent the system furniture composing desks, panels, cabinets, and round discussion tables etc. while the white square marks indicate the chair positions, the individual workspace points for the VGA measures.

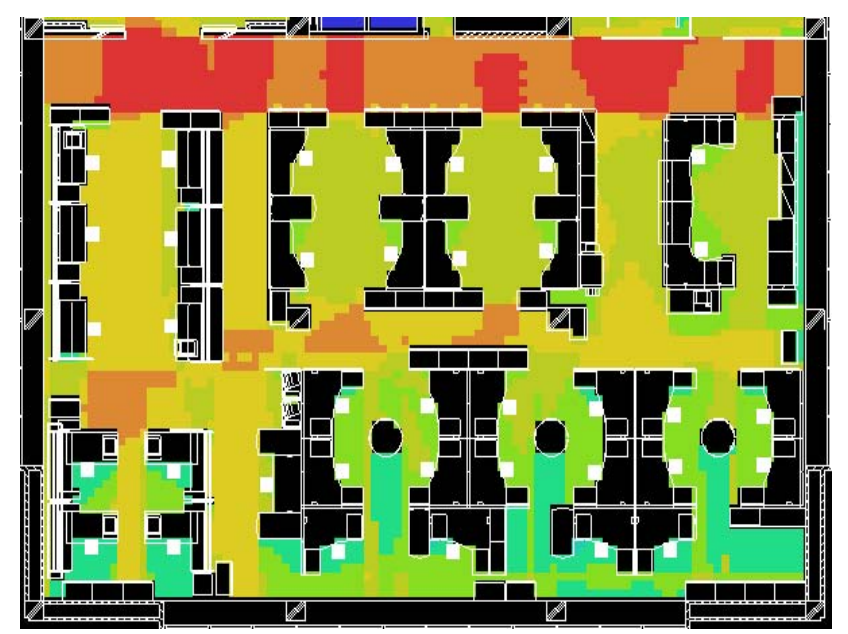

Figure 1. 4th Floor - Visual Integration Tek1 
In the VGA maps, as a spatial point gets to a high value of the entitled VGA measure, for example visual integration Tekl in Figure1 and visual entropy in Figure 2, its color turns to red.

On the other hand, as a spatial point gets to a low value of the measure, it becomes blue. Thus, based on this color spectrum, a map illustrates the visibility states of all the spatial points in terms of each VGA measure. For instance, the areas in red show the spaces with high visual integration Tekl in the case of Figure 1 which are likely to be around pathways on the floor. In the case of Figure 2, areas of high visual entropy tend to be around deep corners where visually closed spaces are linked to open pathways, creating large visual asymmetries.

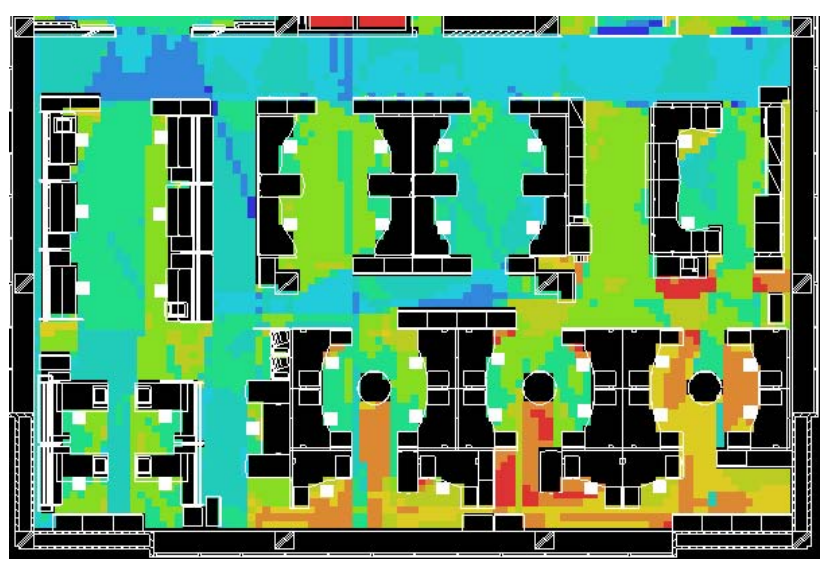

Figure 2. 4th Floor - Visual Entropy

\section{(3) Concentration Privacy}

Based on the operationalized definitions, 'concentration privacy' was measured by the perception of 'difficulty' in task concentration against environmental interruptions or distractions.

Five question items were used for the measure of concentration privacy: I have difficulties in concentrating on my work 1) because of the interruptions caused by conversation requests; 2) because of the open views; 3) because of over-heard speech; 4) because of the general noise in the office, and 5) I have difficulties in continuously concentrating on work at my desk. The questions are answered by 5 point scale:

$\begin{array}{ccccc}\text { Agree } & +1 & \text { Neutral } & & \text { Disagree } \\ +2 & & 0 & -1 & -2\end{array}$

Additionally, two questions were asked to explore the related behavior: 1) the frequency of night-hour working, 2) the amount of tasks difficult to perform in the office during the work hour.

\section{(4) Group Relations}

'Task coordination' was measured by three items: 1) Degree of team members' cooperation for my work problem; 2) Degree of team members' understanding of my work; 3) Degree of decision making speed among team members. 'Informal relationship' was measured by three questions: 1) Degree that I sense a 'bond' with my team members; 2) Degree that I sense 'friendship' with my team members; 3) Degree that I have 'trust' in my team members. The six items were answered on the same scale:

$$
\begin{array}{ccccccc}
\begin{array}{c}
\text { Very High } \\
+3
\end{array} & +2 & +1 & \begin{array}{c}
\text { Neutral } \\
0
\end{array} & -1 & -2 & \begin{array}{c}
\text { Very Low } \\
-3
\end{array}
\end{array}
$$

\section{(5) Procedure}

Based on the CAD maps, six VGA measures of individual workspace are obtained from the chair point (node cell) by Depthmap. The privacy questionnaires distributed via group email were collected by email or in paper. Then, the privacy and group relations measures were recorded into a table corresponding the participants' workspace VGA measures.

\section{ANALYSIS AND DISCUSSION}

For the analysis, two types of statistical techniques were used. 1) Spearman's rank correlation was applied to investigate relationships between the workspace VGA measures and the occupants' privacy and group relations scores, and 2) t-test was administered to observe whether there is any direct effect of each VGA measure on the behavioral scores. Spearman's rank correlation was chosen due to the non-parametric characteristics of the VGA data whereas ttest was used since the privacy and group relations data complied with the parametric assumptions.

A full list of 136 workers was adopted for the correlation study while two groups of people (the upper 50 and the lower 50) were drawn from each list of the VGA measure for the group comparison analysis. The results of two statistical analyses are incorporated into the same table of concentration privacy and of group relations respectively in order to integratively discuss the two statistics.

Table 1 represents the analysis of concentration privacy in relation to research question 1. First, Spearman's rho correlations show that all the VGA measures, except visual connectivity, are significantly correlated with 'continuous concentration difficulty' (1) and 'the amount of tasks difficult to perform in the office during the work hour' (7). The positive correlations indicate that as the workspace visual integration values increase, the occupants' difficulties in performing continuous concentration (1) and the amounts of tasks difficult to perform during the work hour (7) likewise arise as for the correlation degrees.

The low inverse correlations in the table indicate that as the visual mean depth and visual entropy of workspaces increase, workers tend to express reduced problems for continuous concentration (1) as well as the task amounts difficult to perform in the office though the relationship strengths are weak. 
Table 1. Five VGA Measures for Concentration Privacy and the Related Behavior

\begin{tabular}{|c|c|c|c|c|c|c|}
\hline Spearman's rho correlations and t-tests & $\begin{array}{l}\text { Visual Con- } \\
\text { nectivity }\end{array}$ & $\begin{array}{c}\text { Integration } \\
\mathrm{HH}\end{array}$ & $\begin{array}{l}\text { Integration } \\
\text { P-value }\end{array}$ & $\begin{array}{c}\text { Integration } \\
\text { Tekl }\end{array}$ & $\begin{array}{l}\text { Mean } \\
\text { Depth }\end{array}$ & $\begin{array}{l}\text { Visual En- } \\
\text { tropy }\end{array}$ \\
\hline 1) Difficult Continuous Concentration & & $.184^{*}$ & $.184^{*}$ & $.183^{*}$ & $-.185^{*}$ & $-.199 *$ \\
\hline \multicolumn{7}{|l|}{ 2) Interrupted by Talk: for Concentration } \\
\hline 3) Distraction by View: for Concentration & $.197 *$ & & & & & \\
\hline 4) Distraction by Speech: for Concentration & & & & & & $-.175^{*}$ \\
\hline 5) Distraction by Noise: for Concentration & & & & $.189 *$ & & $-.199 *$ \\
\hline 6) Night Hour Work FQ in a Month & & & & & & $-.176^{*}$ \\
\hline 7) Task Amount (\%) Difficult to do in the Office & $.176^{*}$ & $.174 *$ & $.186^{*}$ & $.215^{*}$ & $-.184^{*}$ & $-.182 *$ \\
\hline
\end{tabular}

* Significant Spearman' rho correlation at $\mathrm{p}<.05$ level, $\mathrm{N}=136,2$-tailed; Empty cells indicate non-significant results

+ Cells in grey: significant $\mathrm{t}$ statistics at $\mathrm{p}<.05$ level, $\mathrm{df}=98$ (lower 50 vs. upper 50 out of 136), 2-tailed - VGA measures as IVs

However, the low correlation results indicate that relationship strengths are generally weak and inconsistent between the VGA measures and the privacy scores. The only measure which exhibits relatively consistent associations with the privacy measures is 'visual entropy'. This is also reflected on the $t$ statistics in that visual entropy is the only VGA measure which discriminates workers' responses of privacy conditions for task concentration concerning speech distraction (4), noise distraction (5) as well as continuous concentration difficulty (1). Furthermore, visual entropy distinguishes those workers doing frequent nighthour work from the workers infrequently doing it (6) and also those workers having large amounts from the workers having small amounts of tasks difficult to perform in the office during the work hour (7) (Table 1).

As for the extended measures of workspace privacy behavior (6 7), visual integration Tekl produced a significant group difference result on the measure of workers' task amounts difficult to perform at the desks during the work hour (7). The significant t-test result indicates that workers at the workspaces of high visual integration Tekl values express having more tasks difficult to perform in the office than the workers with low visual integration Tekl scores.

Guided by the inverse correlation signs, the significant t-test results of the effect of visual entropy on the concentration privacy measures can be interpreted that workers at the workspaces of low visual entropy, as compared with of high visual entropy, experience more privacy problems for continuous task concentration specifically due to speech and noise distraction. Furthermore, workers at the workspaces of low visual entropy tend to do more frequent night-hour work (6) while having more amounts of tasks difficult to complete in the office (7) than the workers' at high visual entropy.

Since a workspace of low visual entropy is where the visibility and accessibility to all the neighboring workspaces are close due to high spatial integration along the lines of movement - regardless of the amount of visible areas, the workers at these spatial points tend to receive a large amount of overheard speech as well as general noise from neighboring workspaces thus experience more privacy problems for task concentration. These problems seem to affect the workers, resulting in a large amount of unfinished tasks during the work hour which lead to frequent night-hour work behavior.

Overall, it is plausible to state that visual entropy appears to be more reliable in explaining and predicting the occupants' concentration privacy than the other visual integration measures because it consists of not only the information of workspace visibility but also accessibility which further accounts for the interaction aspect of privacy issue (see Sundstrom, 1986). In other words, the present finding implies that workspace visibility alone exert limited effects on privacy behavior for task concentration.

In other words, the findings suggest that the visual integration models in VGA analysis contain limited explanatory values directly applicable to the privacy 'behavior' because privacy measures in the study account for not a mere sense of having visual privacy or not at workspace but the actual 'difficulty' the occupant experience in pursuing work activities.

This is one of the main reasons that there are many nonsignificance or low levels of statistical significance in the table because of the nature of concentration privacy measures in the study. On the other hand, it means that any significant finding carries highly practical implications of the VGA data for workspace privacy issues.

Table 2 presents Spearman's rho correlations and t-test results of the VGA measures for group relations in relation 
to research question 2. The table shows that most VGA measures are not associated with group relations values except 'trust' (6) with which three visual integration measures (HH/P-value/ Tekl) and visual mean depth are significantly associated at relatively low levels.

Table 2. VGA for Group relations

\begin{tabular}{l|l|l|l|l|l|l}
\hline $\begin{array}{c}\text { Spearman's rho } \\
\text { and t-tests }\end{array}$ & $\begin{array}{c}\text { Visual } \\
\text { Connect }\end{array}$ & $\begin{array}{c}\text { Integ. } \\
\text { HH }\end{array}$ & $\begin{array}{c}\text { Integ. } \\
\text { P-value }\end{array}$ & $\begin{array}{c}\text { Integ. } \\
\text { Tekl }\end{array}$ & $\begin{array}{c}\text { Mean } \\
\text { Depth }\end{array}$ & $\begin{array}{c}\text { Visual } \\
\text { Entropy }\end{array}$ \\
\hline 1) Problem Coop'n & & & & & & \\
\hline 2) Task Underst'ng & & & & & & \\
\hline 3) Decision Speed & & & & & & \\
\hline 4) Bond & & & & & & \\
\hline 5) Friendship & & & & & & \\
\hline 6) Trust & & $.199 *$ & $.169 *$ & $.222^{*}$ & $-.170 *$ & \\
\hline
\end{tabular}

++ Data interpretation manner follows Table 1 .

The significant results can be interpreted in two ways according to the correlation sign. For the positive sign, the results indicate that as the VGA visibility scores increase workers' sense of trust in team members also arise. For the negative sign, an inverse association between visual mean depth and team trust is implied that as visual mean depth increases workers' sense of trust in team members diminishes. Furthermore, $t$ statistics support to state that workspace visual integration Tekl is a reliable visibility data to predict whether a member in a team will possess a strong or weak sense of team trust.

The finding generally suggests that as workspace visibility gets close and paths get shortened (least number of turns) between team members, their sense of trust in one another likewise become strengthened. This finding may be explained by the assumption that workspace open views and close proximities within certain physical boundaries promote group privacy which affects the occupants' informal relationships (see Sundstrom, 1986).

In contrast, the non-significant results of VGA measures with the other group relations scores seem to indicate that workspace VGA may not be directly interpreted for formal relations in a team such as problem cooperation (1), task understanding (2), and decision speed (3), and also for such informal relationship as team bond (4) and friendship (5). The finding suggests that VGA application for formal relationships and interactions should be accompanied by the understanding of relevant social and organizational factors as the context of the space-behavior link (e.g. Rashid and Zimring, 2003). This finding seems to support the previous finding that spatial layout takes an indirect role for task-related interpersonal behaviors while a direct effect for informal relations (see Sundstrom, 1986; McCoy, 2002).
Nevertheless, the distinctive result of trust from bond and friendship measures in relation to the visibility data may be interpreted that participants perceived the term 'bond' and 'friendship' differently from 'trust' though they were assumed as a single factor of 'informal relationship in the study. This finding reserves a further investigation in future research.

\section{CONCLUSION}

Low levels of statistical relations between the selected VGA measures and the workplace behavior in the study may be attributable to the confined linkage of the very specific visibility measures with the behavior in the context of small-scale office spaces of certain work characteristics. Nevertheless, the findings in this study seem to support, to a limited degree, the applicability of various VGA models to workplace design research.

The results indicate that, among the VGA measures, 'visual entropy' encompassing both the workspace visibility and accessibility values is the most reliable measure to predict office workers' privacy problems for task concentration although the prediction accuracy is largely subject to the nature of question whether it concerns a degree or a dichotomous answer - significant $t$ statistics and yet low correlations. As for group relations behavior, the visibility integration models generally help to account for the workers' sense of trust in team member relationship however fail to explain the other group relations measures.

Overall, the findings in this study suggest that workspace VGA analyses have a potential to be a useful tool for office planning and evaluation but should be accompanied by other methods in order to account for the social and organizational factors intervening the spacebehavior linkage.

\section{REFERENCES}

Bafna, Sonit (2005) The impact of furniture systems. Implications, 4(12), 5.

Brill, M., Weideman, S., and BOSTI Associates (2001) Disproving widespread myths about workplace design. NY: Kimbell International.

CABE (2005) The impact of office design on business performance. London.

Chang, A. and Bordia, P. (2001) A Multidimensional Approach to the Group Cohesion-Group Performance Relationship. Small Group Research, 32, 379.

Herman Miller (2008) The private-to-open spectrum.

Janz, B. D., Colquitt, J. A. and Noe, R. A. (1997) Knowledge worker team effectiveness: The role of autonomy, interdependence, team development, and contextual support variables. Personnel Psychology, 50, 877-904.

Kupritz, V. (2000) Privacy management at work: A conceptual model. Journal of Architectural and Planning Research, 17, 47-63.

McCoy, J. (2002) Work environments. In R. Bechtel \& R. Churchman (Eds.), Handbook of Environmental Psychology. New York: Johan Wiley \& Sons, Inc. 
Peponis, J., Bafna, S., Bajaj, R., Bromberg, J., Congdon, C., Rashid, M., et al. (2007) Designing Space to Support Knowledge Work. Environment and Behavior, 39(6), 815-840.

Rashid, M., Wineman, J. and Zimning, C. (2009) Space, behavior, and environmental perception in open-plan offices: a prospective study. Environment and Planning B: Planning and Design, 39, 432-449.

Sonit, B. (2003) Space Syntax: A Brief Introduction to Its Logic and Analytical Techniques. Environment and Behavior, 35, 17-29.

Steen, J., Blombergsson, M. and Wiklander, J. (2005) Useful buildings for office activities. Facilities, 23, 176186.

Penn, A., Desyllas, J. and Vaughan, L. (1999) The space of innovation: Interaction and communication in the work environment. Environment and Planning B., 26, 193218.

Rashid, M. and Zimring, C. (2003) Organizational constructs and the structure of space: A comparative study of office layouts. 4th International Space Syntax Symposium, Georgia Institute of Technology, USA.

Sundstrom, E., Burt, R. and Kamp, D. (1980) Privacy at work: Architectural correlates of job satisfaction and job performance. Academy of Management Journal, 23, 101.

Sundstrom, E. (1986) Work Places: The Psychology of the Physical Environment in Offices and Factories. Cambridge University Press.

Teklenburg, J. , Timmermans, H . and van Wagenberg, A. (1993) Space syntax: Standardised integration measures and some simulations. Environment and Planning B: Planning and Design, 20(3) 347-357.

Turner, A. (2004) Depthmap 4: A Researcher's Handbook", Bartlett School of Graduate Studies, UCL, London

Turner, A. (2001) Depthmap: A Program to Perform Visibility Graph Analysis. 3rd International Symposium on Space Syntax, Georgia Institute of Technology.

Yoo, U. S. (2005) A Conceptual Framework for Comprehending the Underlying Spatial and Organizational Properties in Research Laboratories, Architectural Research, 7(2) 33-45

(Date of Submission : 2010.3.29) 